\title{
Correction to: Principal Components Analysis: An Alternative Way for Removing Natural Growth Trends
}

\author{
Daniela Oliveira Da Silva, ${ }^{1}$ Virginia Klausner,${ }^{1}$ Alan Prestes, ${ }^{1}$ Humberto Gimenes Macedo, ${ }^{1}$ \\ TuOmas Aakala, ${ }^{2}$ and Iuri RoJahn Da Silva ${ }^{1}$
}

Correction to: Pure and Applied Geophysics (2021)

https://doi.org/10.1007/s00024-021-02776-1

The original version of this paper was inadvertently published with an incorrect affiliation for the author Iuri Rojahn da Silva.

The correct affiliation is:

Research and Development Institute-IP\&D, Vale do Paraiba University-UNIVAP, São José dos Campos, SP, Brazil. E-mail: fys.dani@gmail.com.
The original article has been corrected. We apologise for any inconvenience caused to our readers.

Publisher's Note Springer Nature remains neutral with regard to jurisdictional claims in published maps and institutional affiliations.

(Published online July 13, 2021)

The original article can be found online at https://doi.org/10.1007/ s00024-021-02776-1.

1 Research and Development Institute - IP\&D, Vale do Paraíba University - UNIVAP, São José dos Campos, SP, Brazil. E-mail: fys.dani@gmail.com

2 School of Forest Sciences, University of Eastern Finland UEF, Joensuu, Finland. 